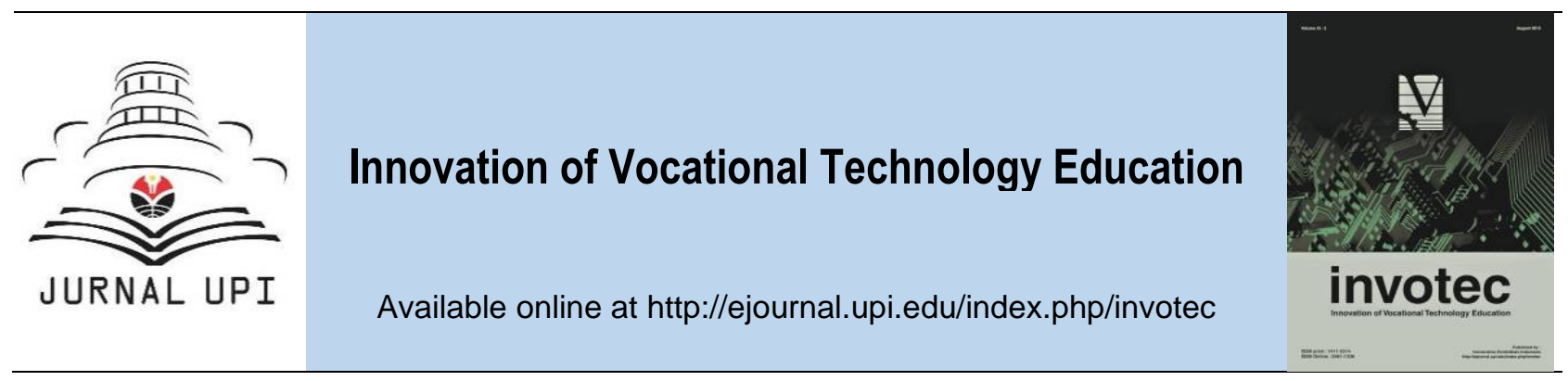

\title{
Gender Relations in the Technical Education Field
}

\author{
Nessy Solihati and Ana \\ Universitas Pendidikan Indonesia, Bandung, Indonesia
}

\section{ARTICLE INFO}

Article history:

Received: 18 June 2019

Received in revised form: 02 July 2019

Accepted: 25 August 2019

Available online: 31 August 2019

Keywords:

relation;

gender;

technique

\section{Authors email:}

nessysolihati@upi.edu

ana@upi.edu

\section{A B S T R A C T}

Harmonious gender relations between men and women is needed to achieve gender equality and gender equity. The purpose of this article is to find out gender relations in engineering, especially mechanical engineering in metal casting. Relationships between male and female students and relations between male and female students and lecturers. The qualitative research is the Phenomenology technique. The informants in this study were 10 students with 4 men and 6 women and a lecturer in a Polytechnic Bandung. The results showed that the relation between male and female students did not make any difference in the process of theory and practice learning. The relationship between lecturers, male, and female students also established without any difference in the men and women gender in carrying out the task of theory and practice learning. A patriarchal culture that hinders interaction between men and women genders and lecturers who used to be attached to the engineering field has begun to disappear. The research development on gender relations in engineering must still be the focus of scientists research.

\section{Introduction}

Education can not be separated from the development, because the development success is the quality education contribution including gender quality in education. Gender equality in education is a condition where women and men got the chance and the same educational treatment (UNGEI, 2012). Gender equality can be said to be similar in education when access to education, the curriculum of education, the development of educators and the achievement of the results of learning which obtained the same for men and women (ACDP, 2013). Besides, several things affect gender equality in education, including school policies, curriculum, the learning process in class and teaching materials. The stereotype of the elderly and people also often influence the decision-making children of women and men in choosing education and careers (Gillen, 2013).

The stereotypes of gender that led to the assumption that women just have a career in the administration field, the child development, education and public health. Whereas men have careers 
in the science field, engineering, technology and law (ACDP, 2013). The administration field, child development, health and education are suitable for women because they are feminine, while the science field, engineering, technology, and law are considered more suitable for men because they are masculine. It makes a difficulty for minority genders member to enter a certain field because of their own culture and perception (Eurydice, 2010). The stereotypes are also caused the treatment differences on one of gender, that is a woman so that prioritize certain party (Popa \& Bucur, 2014). The treatment differences on the gender give an impact on the electoral level high (Silim \& Crosse, 2014).

Rivers (2017) shows that women are under-represented in the higher education, which is only about $20 \%$ of female student who graduated as a bachelor of engineering, and according to Corbett and Hill's research (2015) also shows that only $12 \%$ of women who graduated from the engineering field into a labor force. Other research in US shows that $20 \%$ of women who graduated in the engineering field (Hill, Corbett, \& St. Rose, 2010) and $28 \%$ of women who work in the STEM field (Dasgupta, Scircle, \& Hunsinger, 2015). A low percentage of the female graduate present that gender inequality in the world of academia and the working world in the Science Technology Engineering and Mathematic field (STEM).

Women in STEM education are also often ignored when working on projects or tasks in teams so that they appear to lack in confidence in their performance (Dasgupta, Scircle, \& Hunsinger, 2015; Smith \& Gayles, 2018). Lack of trust in women in engineering also occur when women want a career or apply for a job. Women who still have not reached a bachelor's degree tend to be rejected for a career in the company, because the manager of human resources in some companies still do not have a knowledge about gender equality so they are more receptive to male workers than women (Reuben, 2014; Yatskiv, 2017).

Based on the background regarding gender issues that develop in STEM education researchers want to know the gender relations of women and men as well as student relations with lecturers based on gender in theoretical or practical learning activities in the mechanical engineering department of metal casting especially in terms of interaction. The results of this study are expected to provide knowledge about gender issues to educators and students, also able to be reference in adjusting the curriculum in the engineering field.

\section{Method}

This study is qualitative research. The research technique used in this study is Phenomenology. The population in this study was all students majoring in engineering machinery field of casting metal generation 2016-2018 and lecturer, samples in the research this are 10 students with 4 people male and 6 people women and Lecturers one of the Polytechnic in Bandung. The participant were determined by the procedure Non-Probability Sampling is convenience and accidental sampling. Location of this research is Polytechnic of Manufacturing State Bandung 
(POLMAN), which located in Kanayakan Street 21st, Dago, Coblong-Bandung 40135.This sampling are selected based on the ease of data. The researcher choosing Anyone of the population member which have a various data and which is so easy to get. Otherwise, the researcher also have to pay attention to the ease of access to follows the research process until the data which needed by the researcher. The amount of the Metal Casting Student of this research is shown in the Table 1.

Table 1. Metal casting students in POLMAN Bandung, Indonesia

\begin{tabular}{lccc}
\hline \multicolumn{1}{c}{ Major } & \multirow{2}{*}{ Period } & \multicolumn{2}{c}{ Student } \\
\cline { 3 - 4 } & & Men & Women \\
\hline \multirow{2}{*}{ Metal Casting Engineering D3 \& } & $2018 / 2019$ & 41 & 5 \\
D4 & $2017 / 2018$ & 42 & 4 \\
& $2016 / 2017$ & 42 & 4 \\
& Extension & & 1 \\
\hline
\end{tabular}

The research is shown in more detailed explanation in Figure 1 as follows.

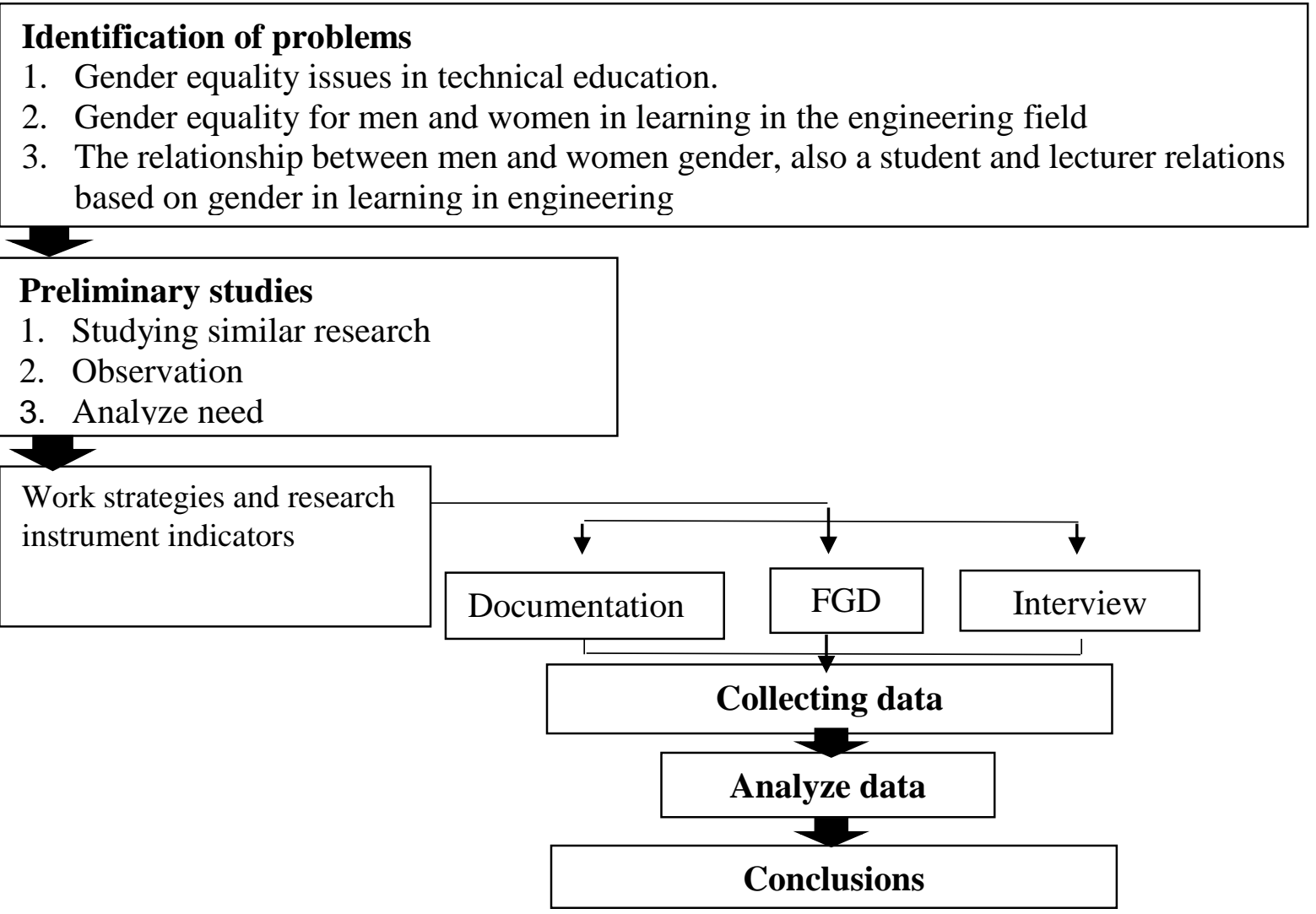

Figure 1. Research flow

The analyzes of this research consist of the activities flow that occur simultaneously, that is the reduction in data presentation and drawing conclusions or verification. The qualitative research have a systematic characteristic from the collection data, choosing data, categorized, comparison, union, and interpretation data (Mc Millan \& Schumacher, 2001). In this research categorization the comparison uses feminist perspective to see the condition of women in the POLMAN which still 
considerate as a minority community in engineering. The Analyze is used to checking and validity checking. The step of the validity checking are:

\subsection{Deep interview}

In-depth interviews mean that the researcher conducts further interviews in the research field until the necessary data collection is reached.

\subsection{Crosschecks field conditions}

Crosschecks are carried out to ensure the experiences expressed by the informants while attending lessons in the field of metal casting following field activities. In addition to the crosschecking of activities, facilities that support gender equality are also carried out by looking directly at the facilities and documented.

\subsection{Triangulation}

- Data validity test of FGD results, observations, interviews, and documentation is done by using triangulation techniques for data sources and data collection techniques

- Comparing observational data on the Polytechnic campus with data from interviews from lecturers.

- Comparing what the informants said in the focus group discussion activities with what happened in the field through direct crosschecks during the learning activities.

- Results confirming of interviews between informants and other informants.

- Compare the interview result with the report of related documents.

\section{Results and Discussion}

The technical environment is more than just the importance of technology and organizational strength. In here the behavior of the gender role is important to be recognized as an engineer, meaning that they look like an engineer, talk like an engineer, and act like as an engineer. The success or failure as an engineer is a one thing that have to do with how well a person socializing in culture techniques. Understanding women's experience in the engineering field and other maledominated occupations requires recognition of the social construction and heterogeneity of their work.

Relations in the engineering field are very important, this is because, in the engineering field, the team is more prioritized. Based on this study result, obtained from matters relating to the higher education engineering field that is well established. This means that the patriarchal culture that was once embedded in the engineering field for women's gender has been removed. The response from 
the informant from one of the Mechanical Engineering Department, Polytechnics in Bandung showed that.

HM" Male students give their opinions on Patriarchal culture as follows.

"Women want a career or learning is their choice, ancient understandings about the differences between women and men have faded, women today are more flexible, they can get information based on info from social media (choices or times are already modern)".

Other opinions expressed by "DG" Male students give their opinions.

"In my opinion, the choice or the right of women and men are free to choose what field they want to work on. As a man, I will not limit the women in doing things as long as it is the will of the woman herself and not against the law and religion".

Female students also expressed their views on patriarchal culture as expressed by "AS" female students as follows.

"In my opinion, patriarchal culture is an influence of the environment and in the selection of the education field that you want to study, depends on the direction of one's interests and should be not influenced by anyone, even pressure from others. Alhamdulillah, in this major in the metal casting campus where I study, I think there is no patriarchal culture".

Another female student "YH" female student revealed:

"Men and women are equal, women do not have to limit herself to the perception of others about their inability, women are also capable like men. So the patriarchal culture is allowed in the education world especially in the engineering field where the majority of the men are so vulnerable that men discriminate against women".

The patriarchal culture rejection in engineering is following the findings of research in learning activities in theory and practice. Interaction between female and male students is normal without discriminating between men and women in the learning process. The interaction of female and male students with the lecturer is also normal without any special or differentiated. This is consistent with the research findings in the expressions form from students and lecturers who become participants or informants.

"YH" revealed the female student.

"In my work sector when carrying out the learning practice process, we are flexible and do not have a standard rules that must be run, but sometimes the instructor recommends doing the light tasks first. However, if I have free time when the process of learning the practice and I am capable, then I will help the work which handled by men in my sector, and friends in my sector are not treating us differently or seen us as a weak women when doing a work which have to be done together".

"AM" male students who agree with gender equality in various fields of "AM" give responses in terms of carrying out practices on campus.

"In certain subjects such as pattern making, there is no difference treatment of male or female gender whether it is easy or difficult for one gender. That is because the work is an individual assignment all of which must do either men or women ".

"HM" male students also commented on gender equality at the time of practice.

"I will invite women if they want to do the work because the work is part of the learning process that must be carried out by all students, whether male or female students. The instructor also 
invited if indeed the work could be done by all students. But there are also courses that emphasize more on experience and "who" is capable of the process. However, if the implementation of the work is heavy, it is better for men to do it first, and that does not mean that women do not participate in carrying out such heavy work and certainly by paying attention, safety and supervision in the implementation. (Equally but seen from experience) ".

"AR" female students express their experiences during practice.

"There are instructors who sometimes choose specific jobs for women, but not all instructors make it easier for women to work. In fact it is not to specialize women in getting jobs that are easier than men. Sometimes I have a feeling of not wanting to be differentiated, but sometimes there is also a feeling or phase that I told to myself, "Indeed this work is really hard and of course it needs the help of my male friend to doing this work ".

Basically, women want to be treated the same when carrying out the work that they want to learn or master in the field of work they are in. Even at certain times for women, especially those who must be in a situation where women have a more sensitive condition "menstruation" even women still want to be equated with men in all respects in the learning process as expressed by "PA" female students.

"In my sector, I do not differentiate and I do not want to be distinguished, either in the process of learning theory or practice, but the portion of the work is only slightly reduced by male friends. And I'm personally fine in such conditions because according to myself as a woman that it's a natural thing".

The views of male and female students in engineering majoring in metal casting at the Bandung state manufacturing polytechnic reject the existence of a patriarchal culture which considers women to be unequal with men and restricts women from various things especially in higher education in the technical field which affect the role of women in society. Women are still identified with work in the domestic area only as a housewife. This culture will further influence the role of women in a broader domain, for example in the public sphere.

\section{Conclusion}

This article presents the research result on the relationship between female students and male students and the interaction of male and female students with lecturers. Based on the results of the study, the relationships that occur between male students and female students have no difference in the learning process of theory and practice during learning in this Metal Manufacturing Polytechnic Bandung period 2016-2019. The relationship between lecturers and male and female students is also established without any difference in the gender of men and women in carrying out the task of learning theory and practice. Judging from the results of research, the development of research on gender relations in engineering must still be the focus of research by scientists. 


\section{References}

ACDP (Education Sector Analytical and Capacity Development Partnership). (2013). Gender Equality in Education in Indonesia. Jakarta.

Corbett, C., and Hill, C. (2015). Solving the Equation: The Variables for Women's Success in Engineering and Computing. American Association of Women's University. 1111 Sixteenth Street NW, Washington, DC 20036.

Dasgupta, N., Scircle, M. M., and Hunsinger, M. (2015). Female peers in small workgroups enhance women's motivation, verbal participation, and career aspirations in engineering. Proceedings of the National Academy of Sciences, 201422822.

Eurydice. (2010). Focus on Higher Education in Europe 2010: New Report on the impact of the Bologna Process. Bologna: EACEA.

Gillen, J. (2013). The Prospects of Measures for the Advance of Gender Equality in TVET. Shanghai.

Hill, C., Corbett, C., and St. Rose, A. (2010). Why so few? Women in science, technology, engineering, and mathematics. American Association of Women's University. 1111 Sixteenth Street NW, Washington, DC 20036.

Mc Millan, J. H., and Schumacher, S. (2001). Study in Education. New York: Harper Collins.

Popa, O., and Bucur, N. (2014). Gender Discrimination and Educations Practitioners, Reality, Perception, Possible Solutions. Procedia - Social and Behavioral Sciences, 127, 459-463.

Reuben, E. (2014). New Research Proves Gender Bias Extraordinary Prevalent in STEM Careers. New York: Columbia Business School.

Rivers, E. (2017). Women, Minorities, and Persons with Disabilities in Science and Engineering. National Science Foundation.

Silim, A., and Crosse, C. (2014). Women in engineering: Fixing the talent pipeline. Institute for Public Policy Research.

Smith, K., and Gayles, J. (2018). "Girl Power": Gendered Academic and Workplace Experiences of the College of Women in Engineering. Social Sciences, 7 (1), 11.

UNGEI (United Nations Girls Education Initiative). (2012). Gender Analysis in Education. New York.

Yatskiv, I. (2017). Why don't women choose stem? Gender equality in stem careers in Latvia. International Journal on Information Technologies \& Security, 79-88. 